\title{
Turnover intention and related factors among general practitioners in Hubei, China: a cross-sectional study
}

\author{
Yong Gan ${ }^{\dagger}$, Yanhong Gong ${ }^{\dagger}$, Yawen Chen ${ }^{1}$, Shiyi Cao ${ }^{1}$, Liqing Li ${ }^{1,2}$, Yanfeng Zhou ${ }^{1}$, Chulani Herath ${ }^{1}$, Wenzhen Li ${ }^{1}$, \\ Xingyue Song ${ }^{1}$, Jing Li ${ }^{1}$, Tingting Yang ${ }^{1}$, Xiaoxv Yin ${ }^{1 *}$ and Zuxun $\mathrm{Lu}^{1 *}$
}

\begin{abstract}
Background: High turnover among general practitioners (GPS) is a significant challenge in China's efforts to build a sustainable, effective primary care system, but little data is available to help understand and address this issue. The study was aiming at assessing the intention to leave their posts among a sample of GPs and investigating associated factors.

Methods: A cross-sectional survey was conducted between December 12, 2014 and March 10, 2015 in Hubei Province, Central China. A total of 1016 GPs (response rate, $85.67 \%$ ) were investigated by using a structured self-administered questionnaire. A generalized linear regression model was used to identify the associated factors with turnover intention among GPs.

Results: Based on a full score of 24, the average score for GPs' turnover intention was 15.40 (SD = 3.43). $78.35 \%$ of the GPs had a moderate or higher level of turnover intention. Six hundred and thirty one (62.37\%) GPs had ever been exposed to abuse of any kind (physical assault, 18.92\%; verbal abuse, 54.38\%; threat, 33.79\%; verbal sexual harassment, 22.66\%; and physical sexual harassment, 7.59\%). Generalized linear regression analysis indicated that GPs who were male; who had a vocational school or higher; who had a temporary work contract; who were with lower level of job satisfaction; who reported higher scores on emotional exhaustion; who had been exposed to higher frequency of workplace violence were expressed higher intention to leave their present positions.

Conclusion: This study shows that GP's intention to leave general practices is high in Hubei, China. In addition, the prevalence of workplace violence is high among GPs, particularly in the verbal abuse and threat. Measures such as offering permanent contract status, increasing overall job satisfaction, and improving doctor-patient relationship, are needed to moderate GP's turnover intention in order to maintain the foundation of China's three-tier health system.
\end{abstract}

Keywords: Personnel turnover, Primary care, Epidemiology, General practitioners, China

\section{Background}

General practitioners (GPs) are the foundation of any primary healthcare system. They are the main providers of community health service (CHS), providing a wide range of health services and managing referrals to specialist care and hospitals. Their quality and quantity are directly associated with the effectiveness and quality of the health

\footnotetext{
* Correspondence: yinxiaoxv@yahoo.com; zuxunlu@yahoo.com

†Yong Gan and Yanhong Gong contributed equally to this work.

'Department of Social Medicine and Health Management, School of Public

Health, Tongji Medical College, Huazhong University of Science and

Technology, No. 13 Hangkong Road, Wuhan 430030, Hubei, China

Full list of author information is available at the end of the article
}

services of a nation. Such GPs system is widely established in western countries, such as the United States, the United Kingdom (UK), Germany, and Australia.

The latest round of nationwide systemic reform in China was launched in 2009, which aimed to provide affordable, equitable access to quality basic health care for all its citizens by 2020 . The building and strengthening of the infrastructure for primary healthcare was the core task of the reform, supported by infusions of substantial public funding [1]. In 2011, the instructional advice on establishment of GPs system was announced through the Stated Council of China, and it proposed to train qualified and excellent

(c) The Author(s). 2018 Open Access This article is distributed under the terms of the Creative Commons Attribution 4.0 International License (http://creativecommons.org/licenses/by/4.0/), which permits unrestricted use, distribution, and reproduction in any medium, provided you give appropriate credit to the original author(s) and the source, provide a link to the Creative Commons license, and indicate if changes were made. The Creative Commons Public Domain Dedication waiver (http://creativecommons.org/publicdomain/zero/1.0/) applies to the data made available in this article, unless otherwise stated. 
GPs by a variety of ways [2]. In 2015, the Stated Council of China pointed out that strengthening of the infrastructure for primary healthcare was the importance of establishing the grading healthcare system, which needed to promote the gatekeeper role of GPs [3]. Many efforts were taken to strengthen the establishment and expand the supply of primary health workers, especially in the training and recruitment of GPs [4].Primary healthcare workers has achieved the attention and support from the government, leaders and related scholars, and the building of GPs team made an some great progress, however, in China, primary health institutions (community health centers ( $\mathrm{CHCs}$ ) and township health centers (THCs)) have been facing ongoing challenges in the shortage of human resources and turnover of on-post GPs. According to the China Health Statistics Yearbook in 2013, the proportion of GPs among registered physicians was $4.2 \%$ [5], which was lower than the level ranging from $30 \%$ to $60 \%$ of western countries [6, 7]. In 2014, the government has identified training GPs as a top priority and planned to train 300,000 of them by 2020 , an ambitious goal by itself. Retention of qualified health professionals in primary healthcare institutions, especially in poor regions, is even more difficult [4]. According to the development planning of Chinese healthcare systems [8], in 2020, two to three GPs per 10,000 population will be fitted in the healthcare system in providing care to people at different levels in China.

Turnover, a behavior of actually leaving, was an important value in human resources management and maintenance of the current workforce [9].Intention to leave was a future behavior of actually leaving a profession or an organization [10], which was considered as a proxy of turnover [11]. Wide agreement on core of turnover models was developed in westerns countries that dissatisfaction ultimately causes employee turnover [12-16]. Recently, newly proposed models are often an extension or refinement of these models, which were considered as the core/backbone of the contemporary turnover theory [17]. According to the above mentioned models, job satisfaction and organizational commitment have become the mainstay of turnover theory, and they provided the supports to the hypothesis that turnover was preceded by turnover intention, which was preceded by job satisfaction. In addition, many turnover researchers showed that turnover intention is also influenced by other factors, such as burnout $[18,19]$ and workplace violence [20-22]. Thus, this study put forward the hypothesis that burnout, job satisfaction, and workplace violence were preceded by turnover intention.

Several studies have been conducted to investigate turnover and its influencing factors (such as sociodemographic, work stress, job satisfaction and burnout) among GPs in developed countries [23-28]. However, there has been almost no data on the turnover of GPs in China now, owing mostly to the difficulty in data collection. Studies on turnover intention, although indirectly, can offer insight on the issue. Some studies have shown that intention to leave general practices could actually translate into GPs leaving their jobs [10, 29, 30]. Moreover, turnover intention may be indicative of lower GPs work morale [29], absenteeism and lowered performance [31], and help developing preemptive measures to stop the turnover before it occurs. According to the background of healthcare reform strengthening the primary health institutions, if the turnover intention was high among Chinese GPs, it would aggravate the shortage of healthcare human resource, lead to decrease productivity, and affect health services quality. This finally could contribute to negative effect on the China's health-care system reform performance. Thus, assessing the turnover intention among GPs is of critical importance to understand the issue and develop targeted policies to promote the retention of current general practice staff and improvement of primary healthcare in Chinese general practice. To our knowledge, no studies to date have investigated the turnover intention and relevant determinants among GPs in China. This study was to investigate the turnover intention and its influencing factors among GPs who served China's grassroots communities. In light of Chinese health care reforms, the findings of this study would inform policymakers about priority areas to strengthen the primary care institutions in China.

\section{Methods}

Ethics statement

The study protocol was approved by the institutional review boards of Tongji Medical College, Huazhong University of Science and Technology, Wuhan, China. All participants read a statement that explained the purpose of the survey and provided written informed consent before participation in the study.

\section{Study population and sampling}

A cross-sectional study was conducted between December 12, 2014 and March 10, 2015 in Wuhan, Hubei Province (Central China).These GPs worked in $\mathrm{CHCs}$ in urban and THCs in rural areas. Initially, we investigated the situation of turnover intention by interviewing related health managers and leader of primary healthcare institutions in Hubei before designing the questionnaire. The prevalence of turnover intention ranged from $16 \%$ to $38 \%$.Finally the prevalence of turnover intention $(\pi)$ was considered as 0.30 in this study. According to the formula of random sampling formula, $\alpha$ was equal to $0.05, \mu_{\alpha / 2}$ was equal to 1.96 , and $\delta$ was equal to $3 \%$. Thus, it needed an ideal sample size of 896 
according to $\frac{\mu_{\alpha / 2}^{2} \times \pi \times(1-\pi)}{\delta^{2}}$.

A stratified sample design was performed in the study. Firstly, in 2012, there were 2325 primary health institutions ( $\mathrm{CHCs}$ and THCs) in 17 prefecture-level cities of Hubei province, all of which were recruited in this study. Secondly, according to the number of GPs and scales of primary health institutions in Hubei Province, GPs were randomly selected from each primary health institution. Of 3752 eligible GPs, 1186 were randomly selected to attend the health service quality training meeting conducted by Hubei provincial general practice training center, and then these GPs were asked to complete the self-reported questionnaire. A total of 1119 (94.35\%) of selected GPs responded to the survey. All together 103 questionnaires were discarded because of too many missing data or logical errors. Finally, 1016 eligible questionnaires remained, giving a response rate of $85.67 \%$.

\section{Measures}

Dependent variable was the turnover intention of GPs. Turnover intention was measured with a modified version of a turnover intention assessment scale, which consisted of 6 items. The Chinese version of these 6 items was modified according to the studies by Mickael and Spector [32] and Li et al. [33]. The items were rated with a four-point Likert scale, ranging from 1 (never, or strongly impossible) to 4 (always, or very possible) (Table 1).The total score of six items was computed as the score for turnover intention, ranging from 6 , the minimal intention, to 24 , the absolute intention to leave one's job. The scores of $0-6,7-12,13-18$, and 19-24 were assigned for the low, moderate, moderate to high and high degree of turnover intention, respectively [33]. In this study, the Cronbach's alpha coefficient for the scale was 0.74 , indicating a good internal consistency. To reduce information bias, all missing values of turnover intention were replaced with the mean of given participants' responses to other scale items [34]. However, there were still a few missing data among the categorized variables that not filled in, such as age, sex, education level and so on. In addition, we deleted the questionnaires due to logical errors. The logical errors identified as some mismatched socio-demographic characteristics for individuals. For example, a GP reported that age was 30 years old; however, work tenure was more than 15 years. Thus, these questionnaires with the obvious logical errors were discarded.

The independent variables covered sociodemographics characteristics (sex, age, marital status), socio-economic status (education level, average monthly income), and work-related factors (practice setting, work tenure, job title, manager responsibility, contract status, burnout, job satisfaction, and workplace violence). The 22-item Maslach Burnout Inventory (MBI-HSS) [35] was used to assess burnout in three subscales emotional exhaustion (EE, 9 items), depersonalization (DP, 5 items), and personal achievement (PA, 8 items), and respondents rated each item on a seven point Likert scale, ranging from 0 (never) to 6 (every day). Higher scores on the EE and DP subscales correspond with higher degrees of burnout, while PA is inversely correlated with burnout. Summary scores for the subscales were achieved by adding the individual item scores and inputting mean values for missing scores if a maximum of two items were missing for $\mathrm{EE}$ and $\mathrm{PA}$ and one item was missing for DP. The Cronbach's alphas for the MBI-HSS, EE, DP, and PA were $0.85,0.91,0.87$ and 0.90 , respectively.

Job satisfaction reported by Shi et al. was measured with 11 items using a five-point ordinal scale ranging from 1 (very dissatisfied) to 5 (very satisfied), including three dimensions: satisfaction on relationship (4 items), satisfaction on personal development (3 items) and satisfaction on basic demand (4 items). This is a reliable and valid instrument for measuring job satisfaction among Chinese primary care providers [36]. The score of job satisfaction ranges from 11 to 55 . In this study, the Cronbach's alpha for the job satisfaction was 0.88 .

The Chinese version of Workplace Violence Scale (WVS), developed by Wang et al. [37], was with a good reliability and validity instrument for measuring the incidence of workplace violence when applied to medical

Table 1 Turnover Intention Scale

\begin{tabular}{|c|c|c|c|c|}
\hline Items & $\begin{array}{l}\text { Often/Strongly } \\
\text { possible }\end{array}$ & $\begin{array}{l}\text { Sometimes/ } \\
\text { Possible }\end{array}$ & $\begin{array}{l}\text { Scarcely/ } \\
\text { Impossible }\end{array}$ & $\begin{array}{l}\text { Never/Strongly } \\
\text { impossible }\end{array}$ \\
\hline \multicolumn{5}{|l|}{ 1. Do you want to leave your present job? } \\
\hline \multicolumn{5}{|l|}{ 2. Do you want to look for other similar job? } \\
\hline \multicolumn{5}{|l|}{ 3. Do you want to look for other different job? } \\
\hline \multicolumn{5}{|l|}{$\begin{array}{l}\text { 4. According to your present status, how much do you feel the possibility } \\
\text { to find the suitable post from other institutions? }\end{array}$} \\
\hline \multicolumn{5}{|l|}{$\begin{array}{l}\text { 5. If you know that there is a suitable post for you in another institution, } \\
\text { how much is the possibility for you to achieve the job? }\end{array}$} \\
\hline 6. Will you to quit your present post? & & & & \\
\hline
\end{tabular}


staff in China. It included 5 items and was measured with a four-point ordinal scale ranging from 0 (never) to 3 (more than 3 times/year) [38, 39]. The score of workplace violence was ranging from 0 to 15 . The higher the score was, the more frequent the workplace violence occurred. Additionally, we reported the prevalence of five types of workplace violence. In this study, the Cronbach's alpha for the workplace violence was 0.82 .

\section{Statistical analysis}

Descriptive analysis was conducted on sociodemographics characteristics, socioeconomic factors, and work-related factors. $T$ test and one-way analysis of variance (ANOVAs) were used to compare the difference in turnover intention among groups. The turnover intention was abnormal (W=0.982843, $P<0.0001)$ and there was no clustering within general practices (intraclass correlation $=0.02, P=0.0869$ ), thus, a generalized linear model was conducted to examine the associations between independent variables and GPs' turnover intention.

Turnover intention, as the dependent variable, was treated as continuous variable. In the multivariable model, independent variables included: age (year in continuous), gender (female and male), marital status (unmarried or widow or divorced, married), education level (high school or below, vocational school, bachelor degree or higher), work tenure (year in continuous), average monthly income ( $<2500,2500 \sim, 3500+$ RMB Yuan), contract status (permanent, temporary), job title(elementary or less, intermediate or higher), manager responsibility (yes, no), practice setting (urban $\mathrm{CHC}$, rural THC), overall job satisfaction (continuous), EE level (score in continuous), DP level (score in continuous), PA level (score in continuous) and workplace violence (score in continuous. Multicolinearity was assessed using the variance inflation factor [40]. All the statistical analyses were performed using Statistical Package for Social Sciences (SPSS, Inc., Chicago, III, Version 13.0), and all tests were two sided with a significance level of 0.05 .

\section{Results}

The main characteristics of the GP participants are reported in Table 2. Of the total of 1, 016 participants (response rate, $85.66 \%$ ), the mean age was 38.70 (standard deviation $(\mathrm{SD})=6.74)$ years. Most GPs $(93.31 \%)$ were married, more than half were male, and half attended bachelor degree or above. Of the participants, the mean duration of healthcare practice was 16.33 $(\mathrm{SD}=7.90)$ years, and $34.12 \%$ had management responsibility; $33.73 \%$ GPs had income per month less than 2500 RMB Yuan. One quarter had a temporary work contract, and more than half located in urban $\mathrm{CHCs}$ practices. The mean score for the workplace violence was $2.33(\mathrm{SD}=3.05)$. Most GPs $(62.37 \%)$ had ever been exposed to workplace violence in the 12-month period. The prevalence of physical assault, verbal abuse, threat, verbal sexual harassment, and physical sexual harassment was $18.92 \%, 54.38 \%, 33.79 \%, 22.66 \%$ and $7.59 \%$, respectively (Additional file 1: Table 1).

The mean score of the turnover intention was 15.40 $(\mathrm{SD}=3.43)$, indicating that the GPs generally had a moderate level of turnover intention. In this study, the percent of GPs with a low, moderate, moderate or higher level turnover intention was $0.98 \%, 20.67 \%$, and $78.35 \%$ respectively. $T$ tests and ANOVA analysis were conducted to compare the difference in mean scores of turnover intention among groups, and the results are shown in Table 2. There were significant differences in GPs' turnover intention in terms of age, sex, education level, contract status, job title, practice setting, job satisfaction, burnout, and workplace violence $(P<0.05)$. There were no significant differences in turnover intention among GPs in terms of marital status, work tenure, average monthly income and manager responsibility.

The results of the generalized linear model to identify factors associated with GPs' turnover intention are shown in Table 3. Gender, education level, contract status, overall job satisfaction, EE level, and exposure to workplace violence were significantly associated with the turnover intention. Those GPs who were male; who had a vocational school or higher; who had a temporary work contract; who were with lower level of job satisfaction; who reported higher scores on the EE; who had been exposed to higher frequency of workplace violence were more likely to show the intention to leave their present position. The adjusted variance in turnover intention explained by the exposure variables was $28 \%$. The explained variance of this model $\left(R^{2}\right)$ was 0.28 . Multicolinearity was not founded since the variance inflation factor of these variables was well below the traditional cut-off value of 10 . No interaction of variables was found.

\section{Discussion}

Promoting the building of grading healthcare system was the most important task of Chinese healthcare reforms. Based on the context of strengthening the primary health institutions was the core of healthcare system in China, assessing the turnover intention and relevant determinants among GPs not only solved the stability of human resources of primary health institutions, but also played a vital role for improving the primary healthcare.

This study investigated the turnover intention and relevant determinants among GPs in Hubei, China. Overall, the study showed that $78.35 \%$ Chinese GPs 
Table 2 Descriptive statistics for determinates and associations with turnover intention

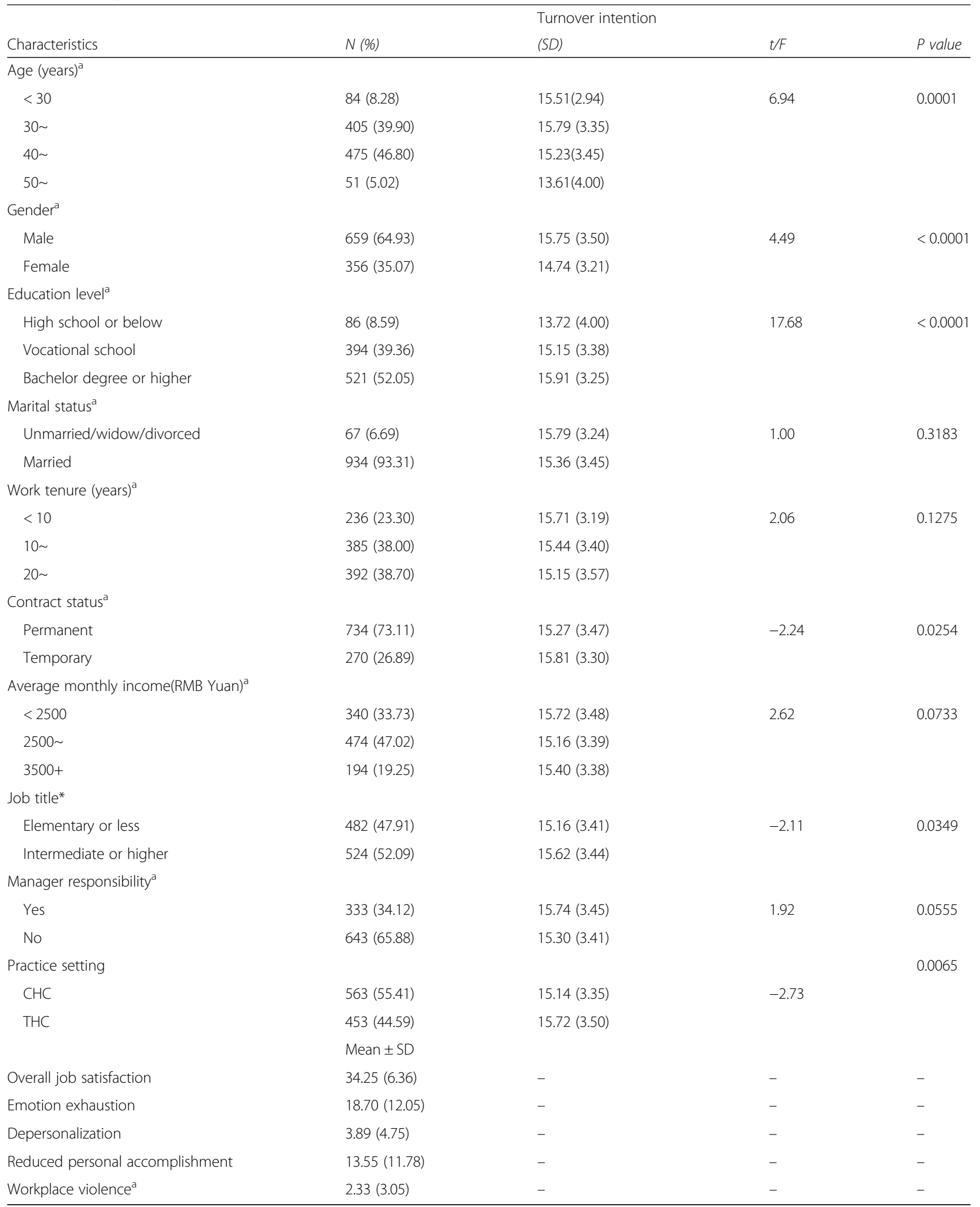

Abbreviations: $C H C$ community health center, $T H C$ township health center

aPercentage of participant with missing data on age $(0.10 \%)$, gender $(0.10 \%)$, education level $(1.48 \%)$, marital status $(1.48 \%)$, work tenure $(0.30 \%)$, contract status $(1.18 \%)$, average monthly income $(0.79 \%)$, job title $(0.98 \%)$, manager responsibility $(3.94 \%)$, and workplace violence $(0.10 \%)$ 
Table 3 General linear model analysis for the association with the turnover intention among GP $(N=922)$

\begin{tabular}{|c|c|c|c|c|}
\hline Variables & Estimate & SE & $t$ & $P$ value \\
\hline Intercept & 23.26 & 1.30 & 17.95 & $<0.0001$ \\
\hline Age & -0.05 & 0.04 & -1.48 & 0.1382 \\
\hline \multicolumn{5}{|l|}{ Gender } \\
\hline Male & 0.55 & 0.23 & 2.36 & 0.0186 \\
\hline Female & 0.00 & 0.00 & - & - \\
\hline \multicolumn{5}{|l|}{ Education level } \\
\hline High school or below & -1.19 & 0.41 & -2.86 & 0.0044 \\
\hline Vocational school & -0.75 & 0.22 & -3.35 & 0.0009 \\
\hline Bachelor degree or higher & 0.00 & 0.00 & - & - \\
\hline \multicolumn{5}{|l|}{ Marital status } \\
\hline Married & -0.003 & 0.40 & -0.01 & 0.9926 \\
\hline Unmarried/widow/divorced & 0.00 & 0.00 & - & - \\
\hline Work tenure (years) & -0.02 & 0.03 & -0.76 & 0.4497 \\
\hline \multicolumn{5}{|l|}{ Contract status } \\
\hline Permanent & -0.67 & 0.23 & -2.86 & 0.0043 \\
\hline Temporary & 0.00 & 0.00 & - & - \\
\hline \multicolumn{5}{|l|}{ Job title } \\
\hline Elementary or less & -0.22 & 0.24 & -0.89 & 0.3747 \\
\hline Intermediate or higher & 0.00 & 0.00 & - & - \\
\hline \multicolumn{5}{|l|}{ Manager responsibility } \\
\hline Yes & 0.19 & 0.23 & 0.82 & 0.4149 \\
\hline No & 0.00 & 0.00 & - & - \\
\hline \multicolumn{5}{|l|}{ Average monthly income (RMB Yuan) } \\
\hline$<2500$ & -0.29 & 0.30 & -0.96 & 0.3386 \\
\hline $2500 \sim$ & -0.37 & 0.27 & -1.39 & 0.1659 \\
\hline $3500+$ & 0.00 & 0.00 & - & - \\
\hline \multicolumn{5}{|l|}{ Practice setting } \\
\hline $\mathrm{CHC}$ & -0.37 & 0.23 & -1.61 & 0.1074 \\
\hline $\mathrm{THC}$ & 0.00 & 0.00 & - & - \\
\hline Overall job satisfaction & -0.18 & 0.02 & -10.25 & $<0.0001$ \\
\hline Emotion exhaustion & 0.05 & 0.01 & 4.45 & $<0.0001$ \\
\hline Depersonalization & -0.01 & 0.03 & -0.52 & 0.6017 \\
\hline Reduced personal accomplishment & -0.01 & 0.01 & -1.22 & 0.2218 \\
\hline Workplace violence & 0.12 & 0.04 & 3.45 & 0.0006 \\
\hline
\end{tabular}

$\mathrm{R}^{2}=0.28 ; \mathrm{F}=20.58, P<0.0001$

Abbreviations: $\mathrm{CHC}$ community health center, $\mathrm{THC}$ township health center

tended to have a moderate to high level of turnover intention. Our findings suggest that the significant factors associated with intention to leave were gender, education level, contract status, overall job satisfaction, EE level, and exposure to workplace violence. In addition, over $60 \%$ of GPs had ever been exposure to any type of workplace violence, and the most prevalent violence was verbal abuse (54.38\%), followed by threat (33.79\%), verbal sexual harassment (22.66\%), physical assault (18.92\%), and physical sexual harassment (7.59\%).

Intriguingly, our finding was inconsistent with this result of the study by Zou et al. [41] in 2015, which showed that GPs were more likely to intend to stay in their current job than physicians. Possible reasons for this discrepancy included a relatively small size (163 GPs), and lacked a standard scale to assess the intention to stay, which may overestimate the effect size. Additionally, the study did not fully investigate other associated factors (such as job satisfaction, burnout and workplace violence) except for socio-demographic characteristics and health status.

One possible interpretation of the high level turnover intention among Chinese GPs was the heavy workload combined with a workforce shortage. In 2011, the Annual Report on the Development of Chinese Health Resources showed that the number of working hours was $53.4 \mathrm{~h}$ per week [42], which was obviously higher than the provisions of $44 \mathrm{~h}$ per week established by the Chinese labor law. In addition, a previous study showed that the harder workload could make physicians suffering from prolonged fatigue [43]. In China, the number of GPs has increased over the past few years, but it remains far shorter than what is needed. By the end of 2013, the number of GPs per 10,000 population was 1.07 [44], which was much lower than the level of developed countries such as the UK (7.2), Greece (3.1), the United States (9.6), Canada (10.4), the Netherlands (6) [45], Norway (8.2), New Zealand (7.6) and Australia (11.09) [46-48]. Another possible explanation was workplace violence, which frequently occurred within healthcare institutions, and the doctor-patient relationship was often unsatisfactory [49]. This finding showed that $60.93 \%$ of GPs was dissatisfied with doctor-patient relationships. In addition, we founded that GPs who were exposure to the workplace violence were more unsatisfactory with doctor-patient relationship than their counterparts $(72.21 \%$ vs. $27.79 \%, P<0.0001)$. A previous study showed that approximately $50 \%$ of health professionals felt bad in terms of relationships with patients [38], and in our study, about $63 \%$ of GPs experienced at least one type of workplace violence in the past 12 months. Third, Chinese GPs who worked in primary healthcare institutions usually had a relatively low income and educational level than those who worked in the secondary or tertiary hospital in the Chinese healthcare system. Notably, Chinese GPs were paid within a reference range set by the government though the range may vary depending on the area and their work tenure. They were more likely to leave their post and to pursue a higher general practice. Intriguingly, in the multivariable linear analysis, there was no statistically significant association between the average monthly income and turnover 
intention among GPs. This requires further investigation at the general practice level. The findings showed that reasonably assigned the workload and improved the income of GPs were two significant measures to ensure that GPs serve as "gatekeepers" in the primary health intuitions of Chinese healthcare system.

There was a significant difference in turnover intention between men and women GPs. We found that the likelihood of intention to leave was much greater for men than for women. One possible explanation to this finding was that men generally experienced higher levels of job dissatisfaction than women accords with previous research [23, 50]. The job satisfaction was negatively associated with turnover intention, as we found in the multivariable linear regression analysis. On the other hand, a previous investigation showed that male GPs were affected more by the work related aspects of the job (practice administration, job demands), while female GPs were affected more by the job interfering with their family life [50], which may reflect the fact that women GPs are more likely to work part time than their male colleagues. This might reflect the finding that male GPs are more likely to intention to leave than their female colleagues.

The association between exposure to workplace violence and the turnover intention among GPs was significant. GPs who had been exposed to higher frequency of workplace violence were found to have higher turnover intention compared to those who had never or less been exposed to it over a 12-month period. Previous studies showed that workplace violence was a strong predictor of workforce participation intentions [51]. In our study, approximately $63 \%$ of GPs had been exposed to at least one type of workplace violence in the past year, of which emotional abuse (EA) was the most prevalent type among GPs. As a serious occupational hazard in the hospital setting, workplace violence could contribute to various adverse consequences for the healthcare professionals, including depression, stress, burnout, sleep disruption, and job dissatisfaction [52-55]. Therefore, improving the relationship between patients and GPs is a critical challenge faced by China that warrants the increasing concern of healthcare managers and researchers. Concerted efforts being undertaken to prevent and minimize the likelihood and consequences of workplace violence in medical practice settings are essential.

Additionally, higher level of EE was also important predictor for turnover intention among GPs in our multivariable linear analysis, which was consistent with previous study [56]. Of note, in our study, we did not observe the statistically significant association between another two burnout sub-scales and turnover intention among GPs. More Chinese studies on investigating the factors associated with $\mathrm{EE}$ are needed, which will help to provide important clue for effective interventions to reduce the intention to leave.

There are several strengths in the present study we want to emphasize. Firstly, to date, this is the first investigation on GPs' turnover intention and the influencing factors in China. Secondly, the large sample size significantly increased statistical power to detect social determinates of GPs' turnover intention. It will play an important role in focusing on strategies to enhance retention as part of the wider range of initiatives for increasing the stability of GPs in primary health institutions.

Some limitations in the current study should be noted. Firstly, since this was a cross-sectional study, the causaleffect was not able to be determined. Longitudinal studies should be considered in further studies. Secondly, all information was collected from a self-reported questionnaire and the response bias was therefore unavoidable. Thirdly, the results need to be treated cautiously as GPs' intentions to leave may not translate into action. However, other research has shown that there is a strong association between intention to leave and actually leaving [57]. Fourthly, the potential influencing factors of GPs' turnover intention are possibly more than those we investigate; we thus failed to identify all of them. Finally, our sample was from one province of China, and thus, the generalizability of our data to other GPs in China may be limited. More studies are needed to enlarge the sample selection and include more potential factors (such as other work-related factors and occupational health factors) affecting GPs' intention to leave their jobs, especially those factors for which specific interventions can be devised to reduce the turnover intention.

\section{Conclusions}

In summary, this study has provided us with some understanding of Chinese GPs' turnover intention and its influencing factors. The turnover intention among GPs in Hubei of China is high, especially in male GPs, GPs with higher education level, with temporary contact status, with lower job satisfaction, with higher levels of EE, and with more frequent exposure to workplace violence. The most prevalent violence was verbal abuse, followed by threat, verbal sexual harassment, physical assault, and physical sexual harassment. These findings could inform healthcare sector and human resource managers about the need to develop concrete strategies for retaining the workforce in general practice.

\section{Additional file}

Additional file 1: The prevalence of different types of workplace violence. (DOCX 15 kb) 


\section{Abbreviations}

CHC: Community health center; CHS: Community health service; DP: Depersonalization; EE: Emotional exhaustion; GP: General practitioner; OR: Odds ratio; PA: Personal achievement; PHC: Primary health care;

THC: Township health center

\section{Acknowledgements}

We would like to thank the general practitioners who participated in this research.

\section{Funding}

This study was supported by Natural Science Foundation of China (NSFC, 71373090, "Study on the gatekeeper policy of community health service"). The funders had no role in study design, data collection and analysis, decision to publish or preparation of the manuscript.

\section{Availability of data and materials}

Data may be made available by contacting the authors.

\section{Authors' contributions}

YOG and ZL conceived and designed the study. YoG, YaG, YC, SC, LL, YZ, WL, $X S, J L$, and TY participated in the acquisition of data. YoG and YaG analyzed the data. YoG wrote the draft of the paper. $\mathrm{YaG}, \mathrm{CH}, \mathrm{XY}$, and $\mathrm{ZL}$ reviewed the paper. YoG revised the paper. All authors have read and approved the final version of this manuscript. $X Y$ and $Z L$ are the guarantors of this work and had full access to all the data in the study and take responsibility for its integrity and the accuracy of the data analysis.

\section{Ethics approval and consent to participate}

The study was approved by the institutional review boards of Tongji Medical College, Huazhong University of Science and Technology, Wuhan, China.

Written informed consent was obtained from all subjects.

\section{Competing interests}

The authors declare that they have no competing interests.

\section{Publisher's Note}

Springer Nature remains neutral with regard to jurisdictional claims in published maps and institutional affiliations.

\section{Author details}

'Department of Social Medicine and Health Management, School of Public Health, Tongji Medical College, Huazhong University of Science and Technology, No. 13 Hangkong Road, Wuhan 430030, Hubei, China. 2Department of Management, School of Economics and Management, Jiangxi Science and Technology Normal University, Nanchang, Jiangxi, China.

\section{Received: 2 March 2017 Accepted: 23 April 2018}

\section{Published online: 24 May 2018}

\section{References}

1. Yip W, Hsiao W. Harnessing the privatisation of China's fragmented healthcare delivery. Lancet. 2014;384(9945):805-18

2. Ministry of Health of the People's Republic of China. A Guidance advice on the establishment of General Practitioners System: 2011 [in Chinese]. http:// www.gov.cn/zhengce/content/2011-07/06/content_6123.htm. Accessed 17 Mar 2017

3. Ministry of Health of the People's Republic of China. A guidance advice on the establishment of grading healthcare system: 2015 [in Chinese]. 2015. http:// www.nhfpc.gov.cn/yzygj/s3593g/201509/c30041e1016a427f9477774c9e864eb4 shtml. Accessed 12 Aug 2017

4. Yip WC, Hsiao WC, Chen W, Hu S, Ma J, Maynard A. Early appraisal of China's huge and complex health-care reforms. Lancet. 2012;379(9818):833-42.

5. National Health and Family Planning Commission of the People's Republic of China. China Health Statistics Yearbook in 2013 [in Chinese]. Beijing: Peking Union Medical College Press; 2014

6. Kroneman M, Meeus P, Kringos DS, Groot W, van der Zee J. International developments in revenues and incomes of general practitioners from 2000 to 2010. BMC Health Serv Res. 2013;13:436.

7. Starfield B. Reinventing primary care: lessons from Canada for the United States. Health Aff (Millwood). 2010;29(5):1030-6.
8. National Health and Family Planning Commission of the People's Republic of China. Development Planning of Health Systems in China between 2016 to 2020: 2017 [in Chinese], http://www.nhfpc.gov.cn/guihuaxxs/s3585u/ 201503/6f403fed54754e4f916bcceac28c197a.shtml. Accessed 30 Jan 2017.

9. Nancarrow S, Bradbury J, Pit SW, Ariss S. Intention to stay and intention to leave: are they two sides of the same coin? A cross-sectional structural equation modelling study among health and social care workers. J Occup Health. 2014;56(4):292-300.

10. Hann M, Reeves D, Sibbald B. Relationships between job satisfaction, intentions to leave family practice and actually leaving among family physicians in England. Eur J Pub Health. 2011;21(4):499-503.

11. Steel RP, Ovalle NK. A review and meta-analysis of research on the relationship between behavioral intentions and employee turnover. The Journal of applied psychology. 1984;69(4):673-86.

12. March JG, Simon HA. Organizations. New York: John Wiley; 1958.

13. Mobley $\mathbf{W H}$. Intermediate linkages in the relationship between job satisfaction and employee turnover. The Journal of applied psychology. 1977;62(2):237-40

14. Mobley $\mathrm{WH}$, Horner $\mathrm{SO}$, Hollingsworth AT. An evaluation of precursors of hospital employee turnover. The Journal of applied psychology. 1978;63(4): 408-14.

15. Lee TW, Mitchell TR. An alternative approach the unfolding model of voluntary employee turnover. Acad Manag Rev. 1994;19(1):51-89.

16. Price JL. Reflections on the determinants of voluntary turnover. Int J Manpow. 2001;22(1):600-24

17. Steel RP, Lounsbury JW. Turnover process models: review and synthesis of a conceptual literature. Hum Resour Manag Rev. 2009:19(4):271-82.

18. Lee RT, Ashforth BE. A meta-analytic examination of the correlates of the three dimensions of job burnout. The Journal of applied psychology. 1996; 81(2):123-33.

19. Green AE, Miller EA, Aarons GA. Transformational leadership moderates the relationship between emotional exhaustion and turnover intention among community mental health providers. Community Ment Health J. 2013;49(4): 373-9.

20. Hills DJ. Associations between Australian clinical medical practitioner exposure to workplace aggression and workforce participation intentions. Australian health review : a publication of the Australian Hospital Association. 2016:40(1):36-42.

21. Ceramidas DM, Parker R. A response to patient-initiated aggression in general practice: Australian professional medical organisations face a challenge. Aust J Prim Health. 2010;16(3):252-9.

22. Heponiemi T, Kouvonen A, Virtanen M, Vanska J, Elovainio M. The prospective effects of workplace violence on physicians' job satisfaction and turnover intentions: the buffering effect of job control. BMC Health Serv Res. 2014:14:19.

23. Sibbald B, Bojke C, Gravelle H. National survey of job satisfaction and retirement intentions among general practitioners in England. BMJ (Clinical research ed). 2003;326(7379):22

24. Gardiner M, Sexton R, Kearns H, Marshall K. Impact of support initiatives on retaining rural general practitioners. Aust J Rural Health. 2006;14(5):196-201.

25. Kuusio H, Heponiemi T, Vanska J, Aalto AM، Ruskoaho J, Elovainio M. Psychosocial stress factors and intention to leave job: differences between foreign-born and Finnish-born general practitioners. Scandinavian journal of public health. 2013;41(4):405-11.

26. Vanasse A, Scott S, Courteau J, Orzanco MG. Canadian family physicians' intentions to migrate: associated factors. Canadian family physician Medecin de famille canadien. 2009;55(4):396-7. e396

27. Rittenhouse DR, Mertz E, Keane D, Grumbach K. No exit: an evaluation of measures of physician attrition. Health Serv Res. 2004;39(5):1571-88.

28. McCarthy G, Tyrrell MP, Lehane E. Intention to 'leave' or 'stay' in nursing. Nurs Manag. 2007;15(3):248-55.

29. Misra-Hebert AD, Kay R, Stoller JK. A review of physician turnover: rates, causes, and consequences. American journal of medical quality : the official journal of the American College of Medical Quality. 2004;19(2):56-66.

30. Buchbinder SB, Wilson M, Melick CF, Powe NR. Primary care physician job satisfaction and turnover. Am J Manag Care. 2001;7(7):701-13.

31. Hayes LJ, O'Brien-Pallas L, Duffield C, Shamian J, Buchan J, Hughes F, Spence Laschinger HK, North N, Stone PW. Nurse turnover: a literature review. Int J Nurs Stud. 2006;43(2):237-63.

32. Michael JE, Spector PE Causes of employee turnover: a test of Mobley, Griffeth, hand and Meglino model. J Appl Psychol. 1982;67(1):53-9. 
33. Li D, Li J. A study on the relationships among role conflict, organizational commitment and intention to quit martrix organizational structure:using emploees from industrial technology research institute as example. Taipei: Institute of imformation Management, National Chiao Tung University; 2000.

34. Shrive FM, Stuart H, Quan H, Ghali WA. Dealing with missing data in a multi-question depression scale: a comparison of imputation methods. BMC Med Res Methodol. 2006;6:57.

35. Maslach C, Jackson SE. The measurement of experienced burnout. J Occupat Behav. 1981;2:99-113

36. Shi L, Song K, Rane S, Sun X, Li H, Meng Q. Factors associated with job satisfaction by Chinese primary care providers. Primary health care research \& development. 2014;15(1):46-57.

37. Wang PX, Wang MZ, Hu GX, Wang ZM, Lang YJ, Jiang JD, Qu JG, Liu SM Study on the relationship between workplace violence and work ability among health care professionals in Shangqiu City. Wei Sheng Yan Jiu. 2006; 35(4):472-4

38. Wu S, Lin S, Li H, Chai W, Zhang Q, Wu Y, Zhu W. A study on workplace violence and its effect on quality of life among medical professionals in China. Archives of environmental \& occupational health. 2014;69(2):81-8.

39. Hesketh KL, Duncan SM, Estabrooks CA, Reimer MA, Giovannetti P, Hyndman K, Acorn S. Workplace violence in Alberta and British Columbia hospitals. Health Policy. 2003;63(3):311-21.

40. Tu YK, Clerehugh V, Gilthorpe MS. Collinearity in linear regression is a serious problem in oral health research. Eur J Oral Sci. 2004;112(5):389-97.

41. Zou Y, Zhang X, Hao Y, Shi L, Hu R, et al. BMC family practice. 2015;16:134.

42. Information Center of National Health and Family Planning Commission. Annual report on the development of Chinese health resources. Beijing: Pecking Union Medical College Press; 2011.

43. Wada K, Arimatsu M, Yoshikawa T, Oda S, Taniguchi H, Higashi T, Aizawa Y. Factors on working conditions and prolonged fatigue among physicians in Japan. Int Arch Occup Environ Health. 2008;82(1):59-66.

44. Ministry of Health of the People's Republic of China.Statistical Bulletin on the Development of Health Service in China: 2012 [in Chinese], http://www.nhfpc.gov.cn/mohwsbwstjxxzx/s7967/201306/ fe0b764da4f74b858eb55264572eab92.shtml. Accessed 20 Sept 2017.

45. Van Greuningen M, Batenburg RS, Van der Velden LF. Ten years of health workforce planning in the Netherlands: a tentative evaluation of GP planning as an example. Hum Resour Health. 2012;10:21.

46. Harrison C, Britt H. General practice - workforce gaps now and in 2020. Aust Fam Physician. 2011;40(1-2):12-5.

47. Crisp N, Chen L. Global supply of health professionals. N Engl J Med. 2014; 370(10):950-7.

48. Economou C. Greece: health system review. Health systems in transition. 2010;12(7):1-177. xv-xvi

49. Zhao M. Evaluation of the third-party mediation mechanism for medical disputes in China. Med Law. 2011;30(3):401-15.

50. Cooper CL, Rout U, Faragher B. Mental health, job satisfaction, and job stress among general practitioners. BMJ (Clinical research ed). 1989; 298(6670):366-70.

51. Hills DJ. Associations between Australian clinical medical practitioner exposure to workplace aggression and workforce participation intentions. Australian health review : a publication of the Australian Hospital Association. 2015;

52. Kivimaki $M$, Virtanen $M$, Vartia $M$, Elovainio $M$, Vahtera J, Keltikangas-Jarvinen L. Workplace bullying and the risk of cardiovascular disease and depression. Occup Environ Med. 2003;60(10):779-83.

53. Shields M, Wilkins K. Factors related to on-the-job abuse of nurses by patients. Health Rep. 2009;20(2):7-19.

54. Hanson GC, Perrin NA, Moss H, Laharnar N, Glass N. Workplace violence against homecare workers and its relationship with workers health outcomes: a cross-sectional study. BMC Public Health. 2015;15:11.

55. Hills $\mathrm{D}$, Joyce CM. Workplace aggression in clinical medical practice: associations with job satisfaction, life satisfaction and self-rated health. Med J Aust. 2014:201(9):535-40.

56. Lin $\mathrm{QH}$, Jiang CQ, Lam TH. The relationship between occupational stress, burnout, and turnover intention among managerial staff from a SinoJapanese joint venture in Guangzhou, China. J Occup Health. 2013;55(6): 458-67.

57. Steel RP, Ovalle NK. A review and metaanalysis of research on the relationship between behavioural intentions and employee turnover. The Journal of applied psychology. 1984;69:673-86.

\section{Ready to submit your research? Choose BMC and benefit from:}

- fast, convenient online submission

- thorough peer review by experienced researchers in your field

- rapid publication on acceptance

- support for research data, including large and complex data types

- gold Open Access which fosters wider collaboration and increased citations

- maximum visibility for your research: over $100 \mathrm{M}$ website views per year

At BMC, research is always in progress.

Learn more biomedcentral.com/submissions 